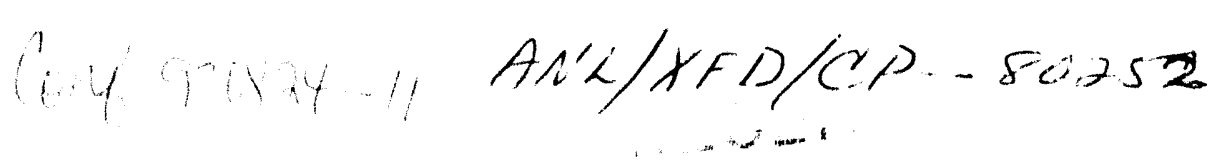

OCT 191933

OST

\title{
Calibration of the Apparent Temperature of Silicon Single Crystals as a Function of Their True Temperature and Their Thickness as Determined by Infrared Measurements.*
}

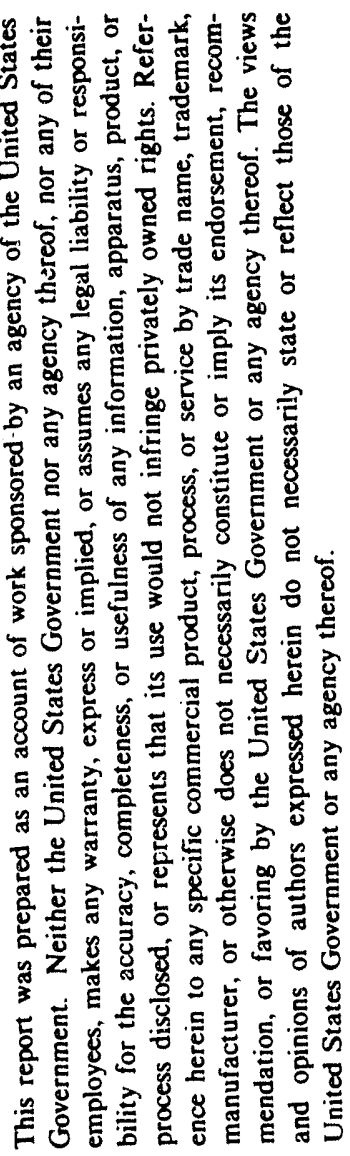

\author{
R.K. Smither and P.B. Fernandez \\ Experimental Facilities Division \\ Advanced Photon Source \\ Argonne National Laboratory \\ Argonne Il 60439
}

September, 1993

The submitted manuscript has been authored
by a contractor of the U.S. Government
under contract No. W-31-109-ENG.38.
Accordingly, the U.S. Government retains a
nonexclusive, royalty-free license to publish
or reproduce the published form of this
contribution, or allow others to do so, for
$U$. S. Government purposes.

jw

*This work supported by the U.S. Department of Energy, BES-Materials Sciences, under contract no. W-31-109-ENG-38 
Poster No. D16 Presented at the SRI conference heid at NIST in Gaithersburg, MD, August 22-26, 1993

Calibration of the Apparent Temperature of Sillcon Single Crystals as a Function of Their True Temperature and Their Thickness as Determined by Infrared Measurements

R. K. Smither and P. B. Fernandez

Advanced Photon Source

Argorine National Laboratory

Argonne, IL 60439 


\title{
Calibration of the Apparent Temperature of Silicon Single Crystals as a Function of Their True Temperature and Their Thickness as Determined by Infrared Measurements
}

\author{
R. K. Smither and P. B. Fernandez* \\ Advanced Photon Source \\ Argonne National Laboratory \\ Argonne, IL 60439
}

\begin{abstract}
Viewing the surface of objects subjected to high heat fluxes with an infrared camera or infrared sensor has proved to be a very effective method for monitoring the magnitude and distribution of surface temperatures on the object. This approach has been quite useful in studies of cooling silicon crystals in monochromators subject to high heat loads. The main drawback to this method is that single crystals of silicon are partially transparent to the infrared radiation monitored in most infrared cameras. This means that the infrared radiation emitted from the surface contains a component that comes from the interior of the crystal and that the intensity of the emitted radiation and thus the apparent temperature of the surface of the crystal depends on the thickness of the crystal and the kind of coating on the back (and/or the front) of the crystal. The apparent temperature of the crystal increases as the crystal is made thicker. A series of experiments were performed at Argonne National Laboratory to calibrate the apparent surface temperature of the crystal as measured with an infrared camera as a function of the crystal thickness and the type of coating (if any) on the back side of the crystal. A good reflecting sulface on the back side of the crystal increases the apparent temperature of the crystal and simulates the response of a crystal twice the thickness. These measurements make it possible to interpret the infrared signals frcin cooled silicon crystals used in past high heat load experiments. A numbar of examples are given for data taken in syrichrotron experiments with high intensisity $x$-ray beams.
\end{abstract}

" Supported in part by the U.S. Department of Energy BES Materials Science under Contract No. W-31-109-Eng-38.

\section{INTRODUCTION}

The very high intensity $x$-ray beams that will be present at the Advanced Photon Source and other third generation synchrotron sources will require that the first optical element in the beamline and, possibly the second optical element as well, be cooled to remove the heat deposited by the $x$-ray beam. ${ }^{1-3}$ In many of the beamlines this heat will be in the 1 to $5 \mathrm{~kW}$ range, ${ }^{4}$ and any failure of the cooling system will require a quick response from safety controi circuits to shut off the beam before damage is done 
to the optical element. In many cases, this first optical element will be a silicon diffraction crystal. Viewing the surface of objects subjected to high heat fluxes with an infrared camera or infrared sensor has proved to be a very effective method for monitoring the magnitude and distribution of surface temperatures on the object. ${ }^{1,3}$ This approach has been quite useful in studies of cooling silicon crystals in monochromators subject to high heat loads. The main drawback to this method is that single crystals of silicon are partially transparent to the infrared radiation monitored in most infrared cameras. This means that the infrared radiation emitted from the surface contains a component that comes from the interior of the crystal and that the intensity of the emitted radiation and thus the apparent temperature of the surface of the crystal depends on the thickness of the crystal and the kind of coating on the back (and/or the front) of the crystal. The apparent temperature of the crystal increases as the crystal is made thicker.

A series of experiments were performed at Argonne National Laboratory to calibrate the apparent surface temperature of the crystal as measured with an infrared camera as a function of the crystal thickness and the type of coating (if any) on the back side of the crystal. A good reflecting surface on the back side of the crystal increases the apparent temperature of the crystal and simulates the response of a crystal twice the thickness. These measurements make it possible to interpret the infrared signals from cooled silicon crystals used in past high heat load experiments. This work has allowed one to go back and correct data taken in synchrotron experiments with high intensity $x$-ray beams and obtain better values for the temperature of the silicon crystals when experiencing high heat loads.

\section{EXPERIMENTAL SETUP}

Figure 1 shows the experimental setup. An infrared camera was used to view a large single crystal of silicon that was shaped into strips of different thickness (see figure 2) so that the IR camera viewed six different thicknesses of silicon at the same time. The temperature of the silicon crystal was controlled with resistive heaters on the sides of the silicon crystal out of view of the IR camera. The apparent temperature of each thickness of silicon crystal was recorded as a function of the actual temperature of the silicon crystal as measured with by two thermal couples mounted on the crystal. The apparent temperatures of the different thicknesses of silicon were compared to the background (room) temperature as measured with the IR camera.

\section{INFRARED MEASUREMENTS}

The difference beiween the apparent silicon temperatures and the background temperature from the IR camera are plotted in figure 3 as a function of the thickness of the silicon. The dashed line in figure 3 is the actual temperature difference between the silicon crystal and the background temperature. The apparent temperature increases rapidly at first and then slowly approaches an equilibrium value near 80 
percent of the real temperature diference of $27.8^{\circ} \mathrm{C}$ The IR camera was set to assume that the object being viewed had an emissivity of 1.0. The equilibrium value of 80 percent is close to the transmission coefficient of the silicon-air interface.

One can calculate, to first order, the observed IR effective temperature by calculating the intensity of the radiation escaping from the surface relative to the IR radiation generated in the crystal. ${ }^{4}$ Some of the various kinds of sequences of events over which one would have to integrate to obtain this average are shown in figure 4 for a simple slab of silicon If the absorption of the infrared radiation is quite low, as it is in silicon, then the photons can be reflected many times as they bounce back and forth between the front and back surface of the crystal. The general form of the equation for the radiation that escapes from the crystal is given by:

$$
I \text { (out) }=I_{0} T_{0}(1-R)\left[1+T_{2} R_{2}+T_{4} R_{4}+T_{6} R_{6}+\ldots .\right]
$$

where $I_{0}$ is the initial flux, $T_{0}$ is transmission fraction or one minus the absorption of the radiation as it travels from the origin of the radiation to the first surface that it encounters, $T$ is the transmission fraction as the radiation travels from one surface to the next, and $R$ is the reflection coefficient at the surface. ${ }^{4}$ If the two absorption terms,

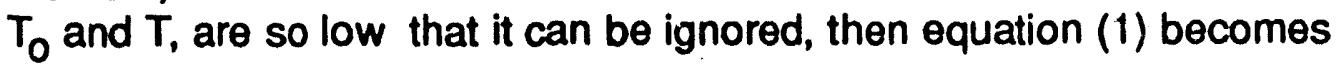

$$
I(\text { out })=I_{0}(1-R)\left[1+R^{2}+R^{4}+R^{6}+\ldots .\right]
$$

The reflection coefficient at these wavelengths is approximately 0.3. Substituting this value in equation (2) we have

$$
I(\text { out })=I_{0}(0.7)[1+0.09+0.0081+0.00073+\ldots]=0.76910
$$

If 10 percent of the radiation were to be absorbed on each pass through the crystal, $T=0.9$ and $T_{0}=0.95$, then the value of $I$ (out) would be slightly lower,

$$
I(\text { out })=I_{0}(0.95)(0.7)[1+0.073+0.0053+0.00039]=0.717 I_{0}
$$

This value comes quite close to the calibration value of 0.76 obtained with $1.54 \mathrm{~cm}$ thick silicon crystal in figure 3 . To the first approximation, the effective emissivity of a thick crystal is equal to the transmission coefficient at the surface or (1-R).

Much work has been done at Argonne on the cooling of the first diffraction crystal in a two crysta! monochromator with liquid gallium. The gallium flows through channels just below the surface of the diffraction crystal. Thus, in order to interpret the data from this type of crystal one needed to know what affect the layer of liquid gallium 
below the silicon would have on the apparent temperature for the silicon crystal. In a second experiment, part of the back side of each step of the silicon crystal was coated with liquid galiium. Two apparent temperatures were recorded for each thickness of the silicon crystal. The temperature differences between these two sets of apparent temperatures and the background temperature are plotted in figure 5. The filled circles are the temperature differences for the case where there is no gallium coating on the back surface of the silicon and the open squares are the temperature differences for the case where there is a coating of liquid gallium on the back surface of the silicon. The real temperature difference between the silicon crystal and the background reference temperature was $19.4^{\circ} \mathrm{C}$ for this experiment. The temperature differences for the gallium coated case are systematically higher that the corresponding noncoated case. The apparent temperature differences from the IR camera for the gallium coated case are similar to the apparent temperature differences observed for a silicon crystal 2.5 to 3 times as thick for the uncoated case.

The presence of channels filled with gallium will complicate this analysis to some degree. ${ }^{1}$ Figure 6 illustrates this complication. In practice, the gallium acts like a metallic, highly reflective surface and looks very similar to the sources near it. The ribs between the slots act like radiation traps, slightly reducing the radiation in this region. In the slotted crystal, this variation can be seen when the crystal is viewed with the IR camera with no beam on the crystal as shown in figure 7 . This data was taken with a Inframetrics 725 camera with the assumed emissivity set equal to unity.

\section{References:}

1. R. K. Smither, G. A. Foster, D. H. Bilderback, M. Bedzyk, K. Finkelstein, C. Henderson, J. White, L. E. Berman, P. Stefan, and T. Oversluizen, Liquid Gallium Cooling of Silicon Crystals in High Intensity Photon Beams, Rev. Sci. Instrum. 60 (1989) 1486-1492.

2. R. K. Smither, Use of Liquid Metals as Cooling Fluids, Workshop on High Heat Load X-Ray Optics, ANL/APS/TM-6 ( Aug. 1989) 83-131.

3. R. K. Smither, W. Lee, A. Macrander, D. Mills, and S. Rogers, Recent Experiments with Liquid Gallium Cooling of Crystal Diffraction Optics, paper presented at the 4th International Conference on Synchrotron Radiation Instrumentation, July 15-19, 1991, in Chester, England. Published in Rev. Sci. Instrum. 63 (1992) 485, and Rev. Sci. Instrum., 63 (1992) 1746-1754.

4. P.J. Viccaro, Power Distribution from Insertion Device Synchrotron XRay Sources, SPIE 1990 Intl. Symposium On Opt., 7/90, San Diego, CA 
5. R. K. Smither, Thermal !naging of Synchrotron beams on Silicon Crystals, Centrale, Paris, on July 7-9, 1992. Published by Eurotherm, "Quantitive Infrared Thermography, QIRT 92", editors D. Balageas, G, Busse, and G,M, Carlomagno, Editions Europeennes Thermique et Industrie, 3, rue Henri-Heine, F-75016, Paris, France.

\section{Figure Captions:}

1. Schematic drawing of experimental setup. The silicon crystal is viewed from the common surface side for all the different thicknesses.

2. Cross section of the silicon crystal used in the temperature measurements. The crystal was viewed from the common face (bottom side in this figure) with the IR camera. The liquid gallium was placed on part of the surface of the stepped side of the silicon crystal.

3. The temperature difference between the room background temperature and the apparent temperature of the silicon as measured by the infrared camera, DT, in centigrade, is plotted verses the thickness of the silicon crystal. The camera asisumed an emissivity $=1.0$ in its calculation of the apparent temperature. The actual temperature difference between the silicon crystal and background room temperature was $27.8^{\circ} \mathrm{C}$.

4. Radiation from a uniform plate that is partially transparent to infrared radiation.

5. The temperature difference between room background temperature and the apparent temperature of the silicon crystal as measured by the IR camera, DT, in centigrade, is plotted verses the thickness of the silicon crystal. The filled circles are data for the case where there is no coating on the back (stepped side) of the silicon crystal. The open squares are the data taken with a coating of liquid gallium on the back surface. The camera assumed an emissivity $=1.0$ in its calculation of the apparent temperature. The actual temperature difference between the silicon crystal and background room temperature was $19.4^{\circ} \mathrm{C}$.

6. Radiation from a slotted crystal. The gallium filled slots are $0.75 \mathrm{~mm}$ wide and $3 \mathrm{~mm}$ tall. The ribs between the slots are $0.75 \mathrm{~mm}$ wide

7. Temperature profile perpendicular to cooling channels in the silicon crystal shown in figure 6 with no x-ray beam on the crystal. Only the slotted portion of the crystal is shown. 


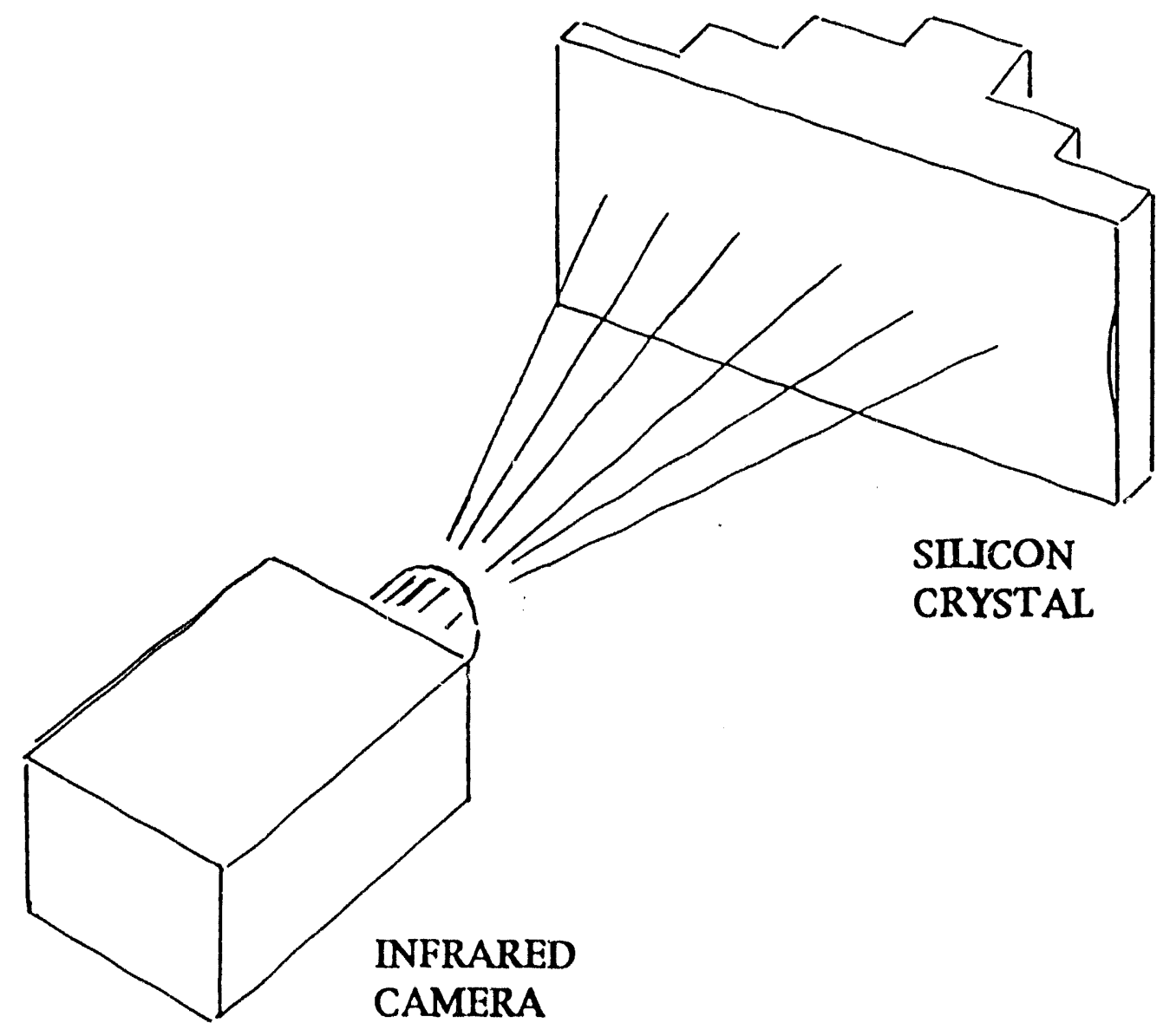


CROSS SECTION OF THE SILICON CRYSTAL

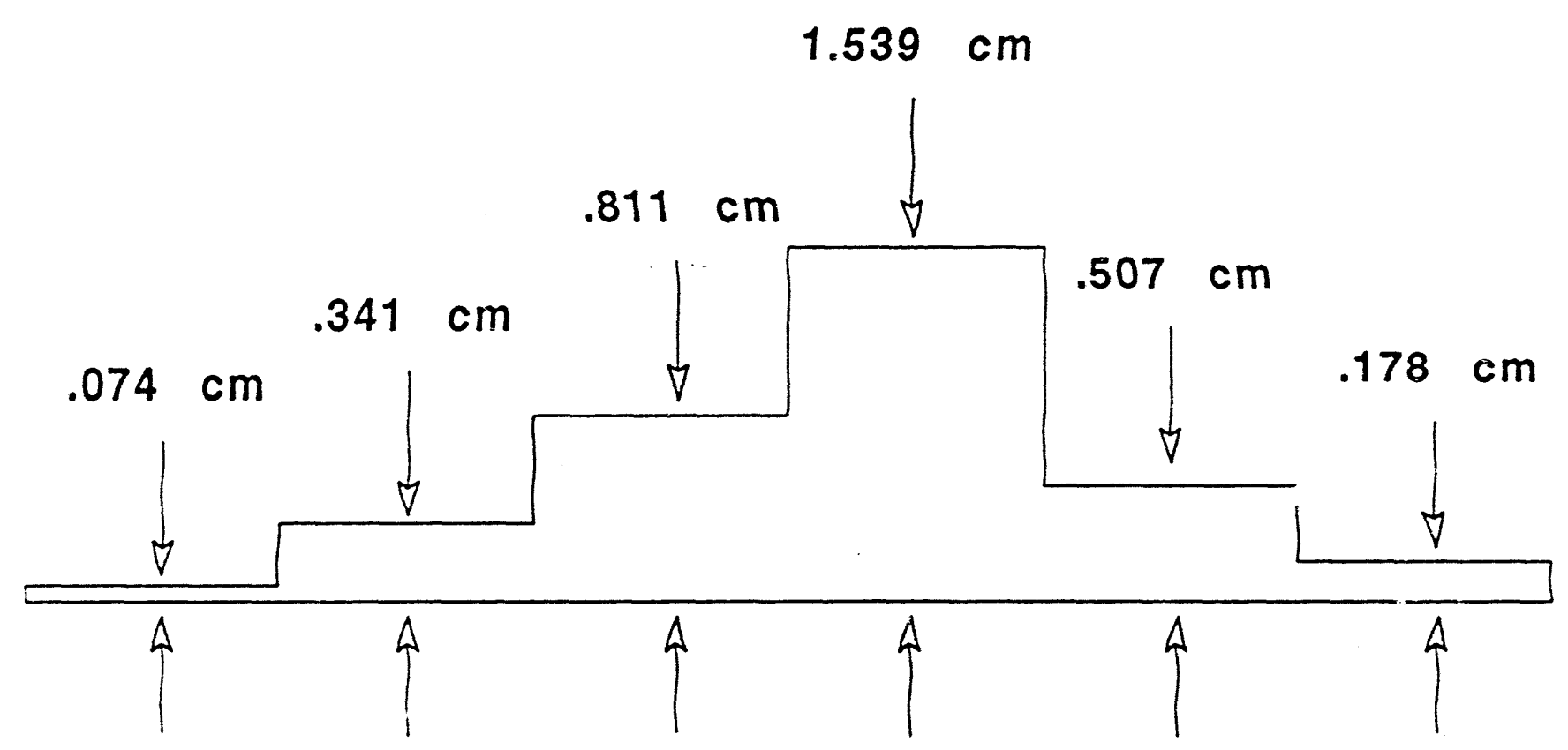




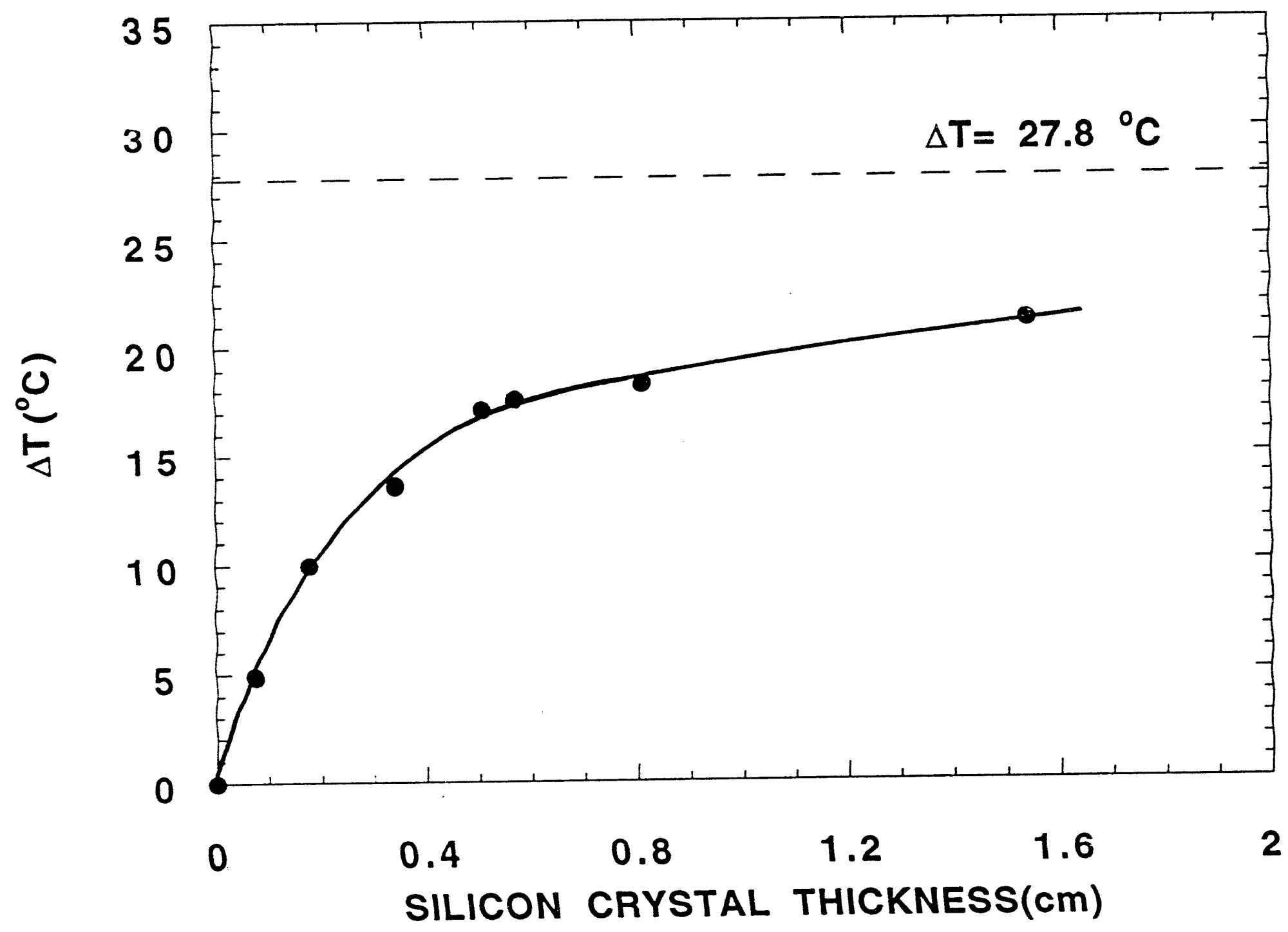




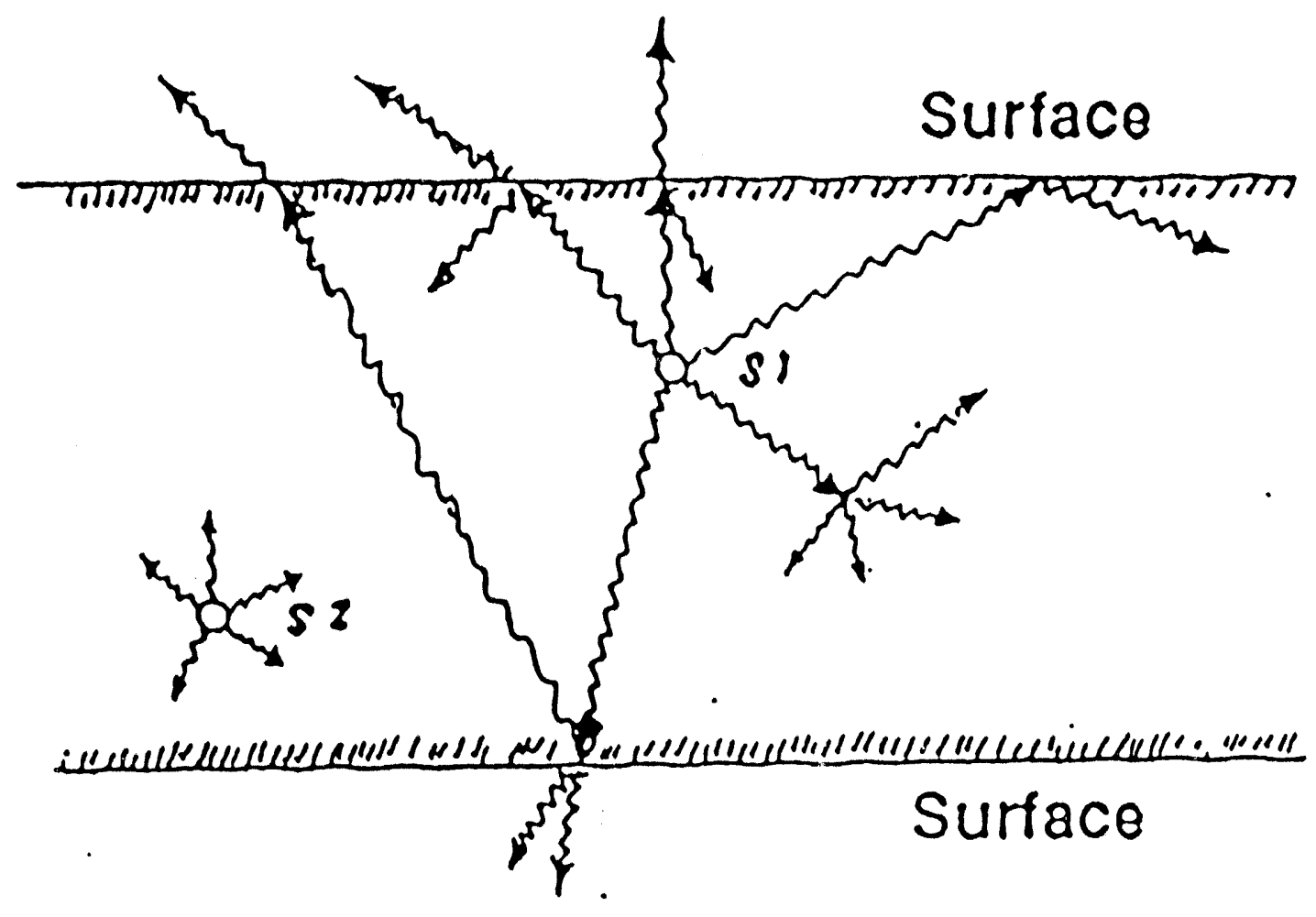

Fic, 4 


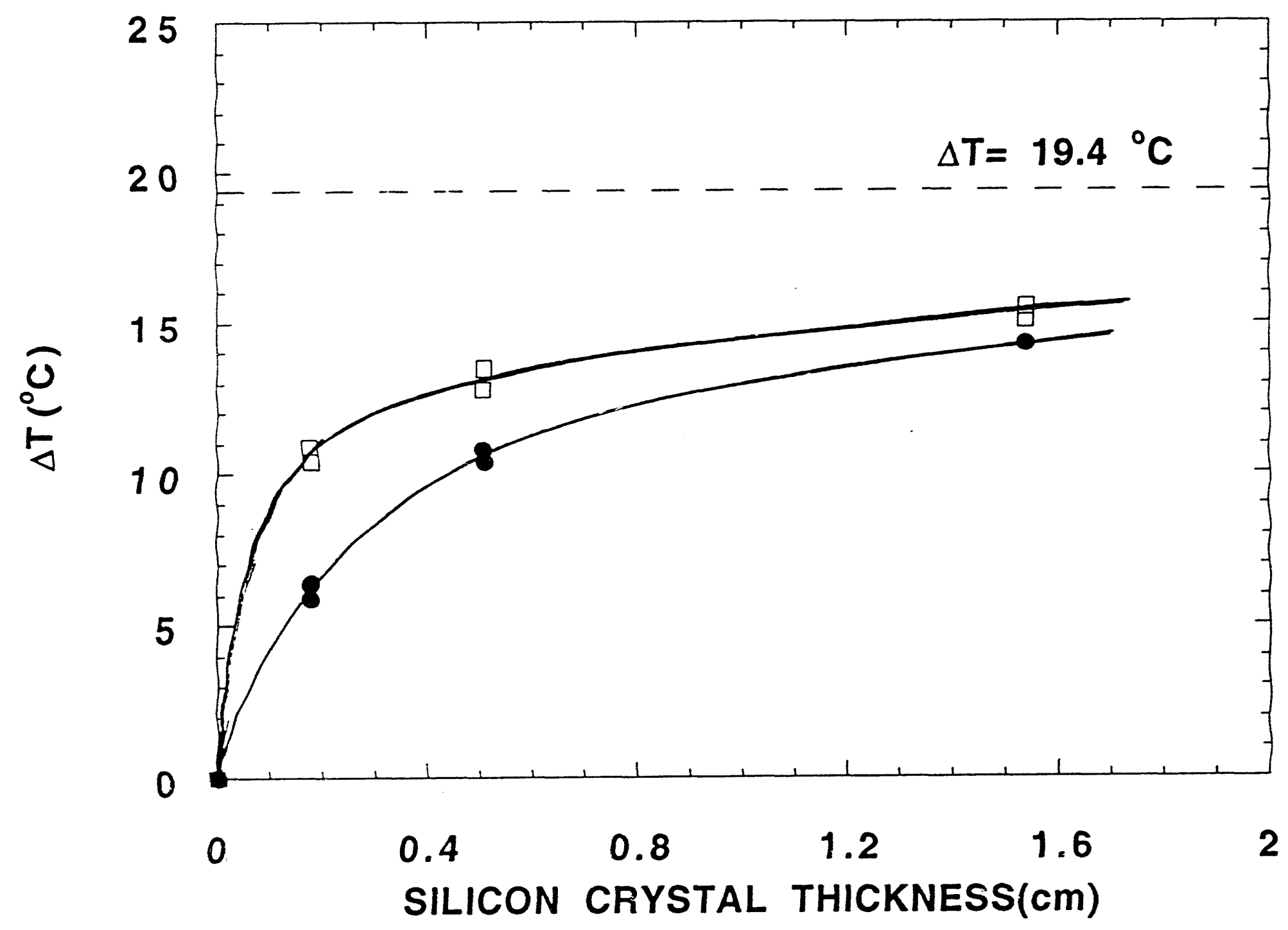




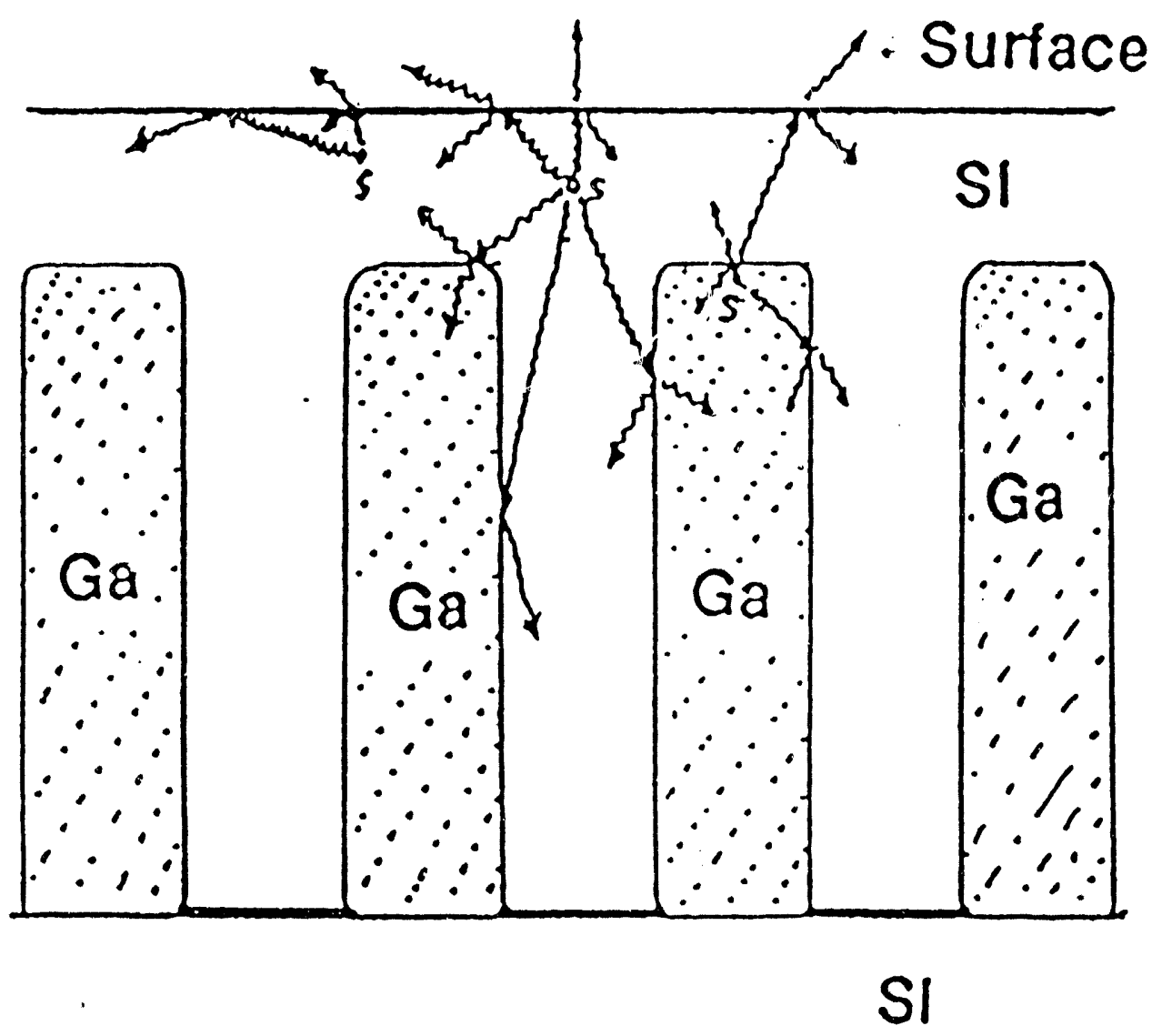

Fis 6 


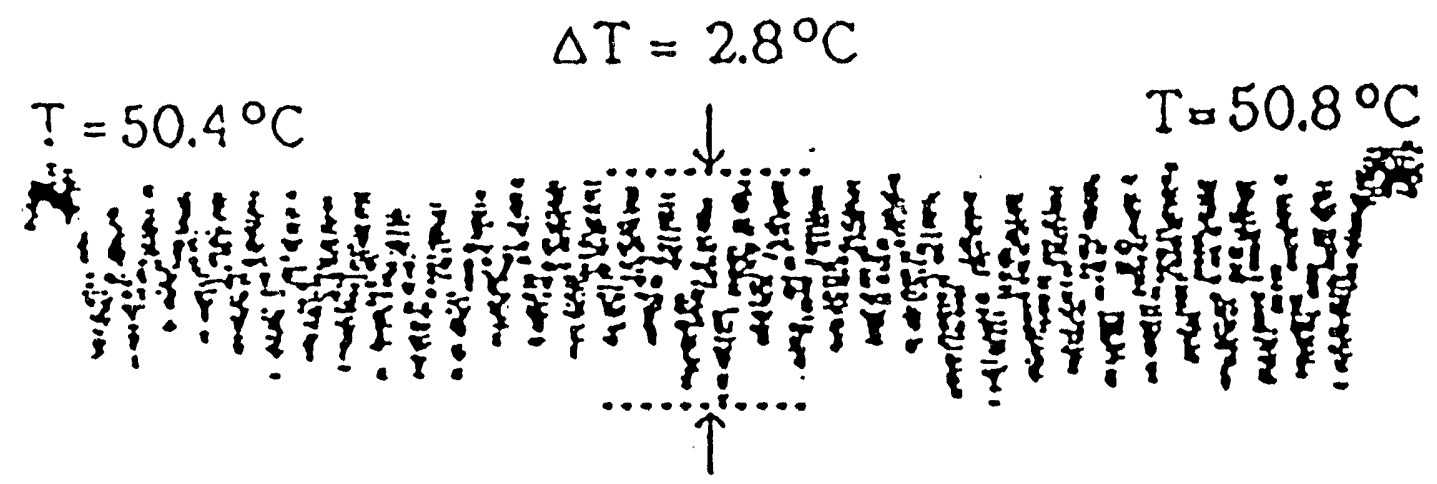



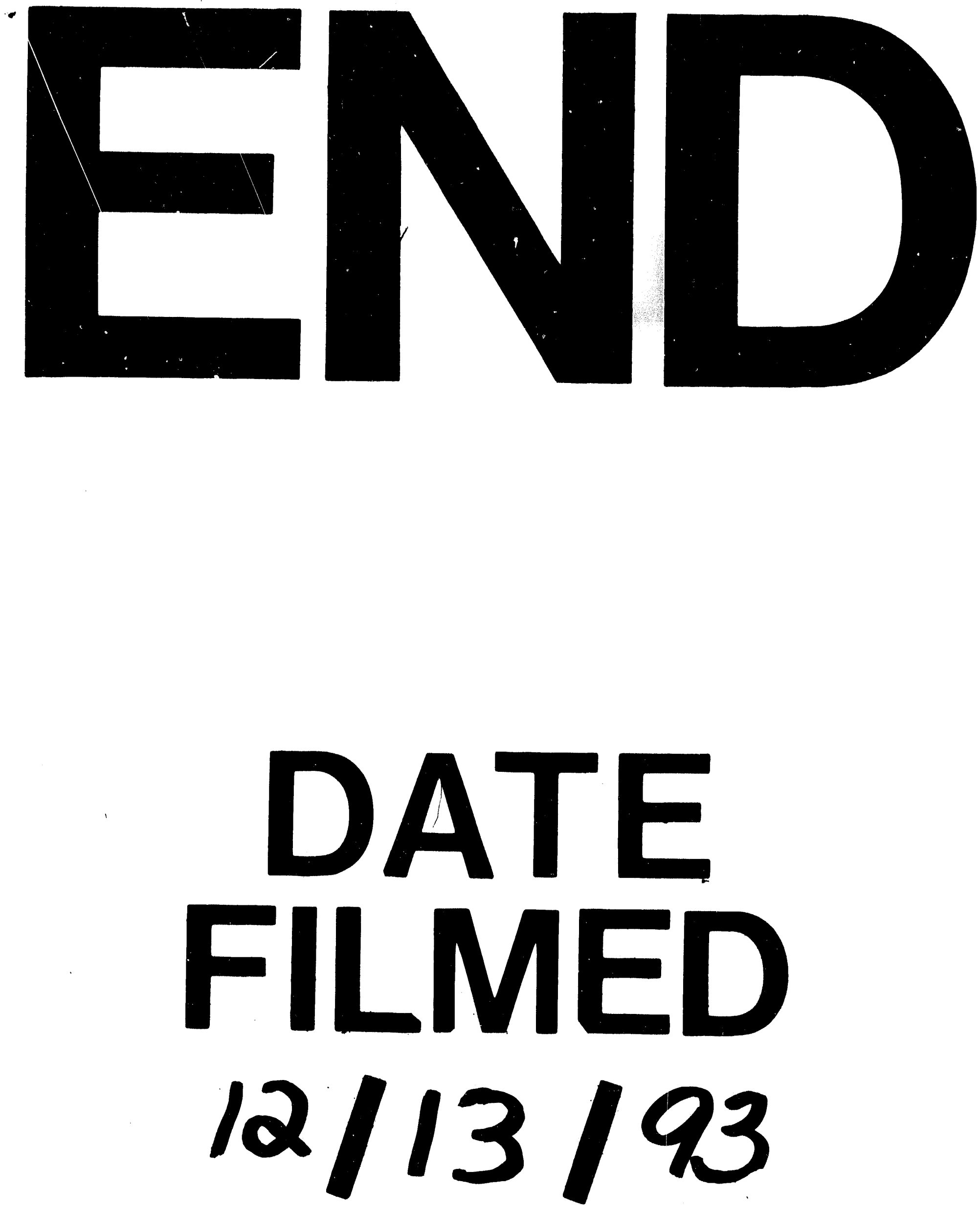
